\section{LITERATURA Y CIENCIA. HACIA UNA INTEGRACIÓN DEL CONOCIMIENTO}

\author{
Gustavo Ariel Schwartz \\ Centro de Física de Materiales CSIC-UPV/EHU \\ https://orcid.org/ 0000-0003-3044-2435 \\ gustavo.schwartz@csic.es \\ Eduardo Berti \\ Escritor \\ ORCID iD: https://orcid.org/0000-0002-1297-1176 \\ eduardoberti@yahoo.fr
}

Cómo citar este artículo/Citation: Schwartz, G. A. y Berti, E. (2018). Literatura y ciencia. Hacia una integración del conocimiento. Arbor, 194 (790): a481. https://doi.org/10.3989/ arbor.2018.790n4006

Recibido: 25 marzo 2015. Aceptado: 25 agosto 2017

RESUMEN: Examinaremos en este artículo las relaciones entre literatura y ciencia a lo largo de los últimos dos siglos, con especial énfasis en el estado actual y en las perspectivas futuras. Veremos aquí que existen profundos vínculos entre ellas como consecuencia de que ambas se nutren de un imaginario colectivo común a la vez que lo alimentan. Analizaremos también diversos aspectos tales como las influencias recíprocas y los desarrollos simultáneos de nuevas ideas y conceptos. En este sentido, comprobaremos cómo los grandes cambios de paradigma se manifiestan muchas veces a la vez en la ciencia, la literatura y otros ámbitos del saber. Finalmente, discutiremos algunos aspectos relativos a la exploración de los espacios comunes entre literatura y ciencia con el objetivo de potenciar las formas de conocimiento a partir de un mestizaje epistémico y metodológico.

PALABRAS CLAVE: Literatura y ciencia; hibridación; imaginario colectivo; método científico; paradigmas; autorreferencialidad; mestizaje.

\section{LITERATURE AND SCIENCE. TOWARDS AN INTEGRATION OF KNOWLEDGE}

Copyright: (C) 2018 CSIC. Este es un artículo de acceso abierto distribuido bajo los términos de la licencia de uso y distribución Creative Commons Reconocimiento 4.0 Internacional (CC BY 4.0).

ABSTRACT: We examine in this article the relationships between literature and science through the last two centuries, paying special attention to the present situation and its future perspectives. We will see that there are deep connections between science and literature since both are fed by (and at the same time feed) common social imagery. We will also analyse different aspects of the many relations between science and literature, such as their mutual influences and the parallel development of new concepts and ideas. In this sense, we will show how the major paradigm shifts are usually expressed simultaneously by science, literature and other fields of knowledge. Finally, we will discuss some aspects related to exploration of the common spaces shared by literature and science, in order to strengthen the forms of knowledge by means of an epistemic and methodological hybridization.

KEYWORDS: Literature and science; hybridization; social imaginary; scientific method; paradigm shifts; self-referentiality; mixing. 


\section{INTRODUCCIÓN}

Los historiadores parecen coincidir en que la bifurcación entre literatura y ciencia comenzó en los siglos XVIII y XIX, cuando ambas áreas del conocimiento se establecieron como instituciones profesionales especializadas (Gossin, 2002, pp. 252-260). A partir de ese momento, las fronteras instauradas arbitraria y contingentemente se fueron solidificando hasta que, hacia finales del siglo XIX y principios del XX, la literatura y la ciencia se convirtieron en carreras universitarias independientes. Para esa época, el contacto entre artistas, literatos y científicos era más bien escaso, y las fronteras institucionales (tanto educativas como profesionales) acentuaban la incomunicación. La difícil relación entre literatura y ciencia alcanzó tal nivel de paroxismo que la indiferencia o el desprecio mutuo se convirtieron en un lugar común, en una especie de cliché intelectual. A esto se sumó el que los escritores, artistas y humanistas manifestaban temor y disgusto frente al reduccionismo y a la mecanización que proponía la ciencia. Al igual que sus predecesores del Romanticismo, los escritores y críticos modernos expresaron una mezcla de miedo y envidia ante el prestigio cultural que estaba alcanzando la ciencia, convertida por entonces en la herramienta más eficaz para adquirir "conocimiento verdadero", una herramienta que amenazaba la posición de privilegio de aquellos. Esta situación contribuyó a dificultar el intercambio de ideas y conceptos entre literatura y ciencia, empujando a cada disciplina a atrincherarse en su propia torre de marfil.

El clímax de tal desencuentro entre literatura y ciencia lo marcó Charles P. Snow en su ya famosa conferencia Rede de 1959 acerca de lo que él denominó "las dos culturas y la revolución científica". Si bien su discurso poseía fuertes componentes políticos y buscaba relacionar la pobreza en el mundo con la falta de conocimientos científicos en los intelectuales que deciden las políticas de estado, su planteamiento puso sobre la mesa un problema que contaba ya más de ciento cincuenta años. El debate lanzado por Snow (y al que F. R. Leavis respondió ferozmente) era una continuación de la polémica victoriana que habían mantenido un siglo antes Matthew Arnold y T. H. Huxley ${ }^{1}$ (Snow, 2000). En cualquier caso, la conferencia de C. P. Snow tuvo una gran repercusión y la controversia se instaló tanto en la esfera académica como en revistas y periódicos de circulación masiva. La polémica acerca de las "dos culturas" abarcaba muchos aspectos que incluían reformas políticas, morales y educativas. Quedaba claro que se había levantado una especie de barrera infranqueable entre ambas disciplinas y que ello estaba minando las posibilidades de desarrollo social, político e intelectual.

Sin embargo, pese a que la incomunicación explícita resultaba más que evidente, no es menos cierto que existía al mismo tiempo un intercambio sutil, involuntario y silencioso. Como veremos en este artículo, las fronteras que circunstancialmente pueden separar diferentes dominios del conocimiento reducen, pero no suprimen, el flujo de información de unos a otros. El pensamiento viaja gracias a la interacción social y a actividades que involucran a personas de diferentes disciplinas; es sin duda la manera más eficiente de hacerlo circular. No debemos ignorar que las fronteras son siempre porosas y que los conceptos suelen filtrarse por pequeñas hendijas permeando todos los rincones de la cultura. La historia de las ideas muestra que cada vez que ha habido cambios sustanciales de paradigma se han producido con relativa simultaneidad en diversos ámbitos culturales (Watson, 2002).

Paradójicamente, hacia la misma época en la que el debate acerca de la divergencia entre las "dos culturas" alcanzaba su apogeo despuntó la publicación lenta y gradual de algunos estudios sobre literatura y ciencia. Estas iniciativas se alumbraron principalmente en departamentos de Historia de las Ideas, Filosofía de la Ciencia, Teoría Literaria y Lingüística. Ciertos estudios se consolidaron a partir de la década de los 80 , cuando se formó una masa crítica de intelectuales dedicados a dichos temas y se organizaron reuniones, conferencias y grupos de trabajo (Gossin, 2002). En 1985 fue fundada en Estados Unidos la Society for $\mathrm{Li}$ terature, Science and the Arts (SLSA), que cuenta actualmente con varios cientos de miembros en activo, prepara conferencias anuales y edita su propia revista (Configurations); y más tarde se crearía en el Reino Unido la British Society for Literature and Science. Lamentablemente, en el mundo hispanohablante los esfuerzos por integrar (o al menos por explorar las relaciones entre) literatura y ciencia, mucho más escasos y dispersos, no han logrado constituir la mencionada masa crítica de investigadores e intelectuales imprescindible para trabajar con orden y sistema.

Si bien existe en la actualidad un consenso bastante amplio a propósito de la necesidad y el valor de los estudios transdisciplinares, es preciso aún encontrar modelos y metodologías que faculten para abordar sistemáticamente las relaciones entre literatura y ciencia. En este artículo nos centraremos en particular en cuatro aspectos que nos parecen relevantes y que no han sido lo bastante tratados en investigaciones 
previas. Rastrearemos primero la relación de la literatura y la ciencia con el imaginario colectivo de cada época. Veremos que, más allá de los gruesos muros de separación entre las disciplinas, se dan conexiones subterráneas e inconscientes que permiten un trasvase permanente de ideas y conceptos entre los plurales ámbitos del conocimiento. Discutiremos luego los problemas y paradojas que aparecen cuando un lenguaje (formal o natural) se mira a sí mismo. Las últimas dos secciones describirán, por un lado, los lazos de la novela policíaca con el método científico y, por otro, cómo ciertos cambios de paradigma a lo largo del siglo XX se han desplegado convergentemente tanto en literatura como en ciencia. Analizaremos, para finalizar, las posibilidades reales de una hibridación entre literatura y ciencia, haciendo especial hincapié en las estrategias susceptibles de impulsar una integración crítica de las distintas formas de conocimiento.

A pesar de que cuenta con grandes escritores como Julio Verne, H. G. Wells, Isaac Asimov o Ray Bradbury, hemos excluido de nuestro estudio a la ciencia ficción. Los textos literarios de este género proponen en general, ya sea en forma de apología o de rechazo, una exacerbación de los logros tecnológicos y una extrapolación del comportamiento social. Sin embargo, la presencia de conceptos científicos o, más latamente, de cuestiones tocantes al conocimiento del mundo, resulta en ellos más bien escasa, y su tratamiento un tanto superficial. Curiosamente, en el resto de la literatura (fuera de la ciencia ficción) tales asuntos suelen manejarse con mayores lucidez y profundidad. Es justo en esas últimas manifestaciones, a la vez menos evidentes y mucho más intensas, donde centraremos nuestro análisis de las interacciones entre literatura y ciencia.

\section{EL IMAGINARIO COLECTIVO}

Al contrario de lo que pudiera parecer a primera vista, el que la literatura y la ciencia se influyan la una a la otra no es algo tan extraño; de hecho, aun sin proponérselo se han influido significativamente a lo largo de la historia. Superando el alejamiento circunstancial entre intelectuales humanistas y científicos, las novedades de cada campo se difunden a través de los medios de comunicación o de otros canales más complejos y sofisticados, y tarde o temprano terminan por infiltrarse en todos los sectores de la cultura. Más sorprendente aún es el hecho de que ciertas ideas surjan a la par en ambas disciplinas, es decir con una diferencia de pocos años y sin que quepa apreciar un condicionamiento recíproco o una conexión causal entre ellas. ¿Es una simple coincidencia, por ejemplo, que el narrador omnisciente comenzara a abandonarse en la literatura al mismo tiempo que en la física desaparecían los sistemas de referencia absolutos? ¿O que Virginia Woolf y Freud se hicieran, casi a la vez, preguntas acerca del inconsciente? ¿Existe alguna relación entre lo que André Gide denominó mise en abyme ${ }^{2}$ y los conjuntos de Cantor?

Historiadores y sociólogos han remarcado el hecho de que muchos descubrimientos científicos (y también tecnológicos) se efectúan de modo más o menos paralelo, sin que los respectivos autores hayan tenido contacto entre sí o conocimiento el uno de los trabajos del otro. Uno de los ejemplos más citados es la formulación del cálculo diferencial realizada independientemente por Newton y Leibniz hacia finales del siglo XVII. Estos "descubrimientos" sincrónicos se dan también en el mundo del arte y de la literatura; incluso se ha llegado a argumentar que los hallazgos múltiples revisten características similares tanto en el campo artístico como en el científico (Lamb y Easton, 1984). Pareciera que, de alguna forma, en cada disciplina y en cada momento histórico la solución a ciertos problemas (o incluso cada uno de los cambios de paradigma) confluyera naturalmente en una determinada dirección. Pero, ¿cómo explicar entonces los descubrimientos concomitantes en diferentes disciplinas? ¿O es que en el fondo no son tan diferentes? ¿Cuál es el punto de contacto, el nexo común entre diversos ámbitos de la cultura y del conocimiento?

La ciencia y la literatura (o el arte) son modos de explorar la realidad, estrategias para comprender el mundo. Difieren en sus métodos, sí; pero se asemejan en sus intenciones. La literatura y la ciencia, dos manifestaciones de la creatividad humana, se nutren en cuanto tales de un imaginario colectivo común. Como bien señala Emmanuel Lizcano Fernández (Lizcano, 2003, p. 4), es "el imaginario [el que] educa la mirada, una mirada que no mira nunca directamente las cosas: las mira a través de las configuraciones imaginarias en las que el ojo se alimenta [...] Cada imaginario marca un cerco, su cerco, pero también abre todo un abanico de posibilidades, sus posibilidades".

Ahora bien, ¿cómo definir el imaginario colectivo si es precisamente allí donde se elaboran las definiciones? Aunque no sea posible definirlo, podemos metaforizarlo: podemos pensarlo como un magma subterráneo en continua ebullición, originando permanentemente formas, ideas, conceptos, precipitando estos en identidades (transitoriamente) fijas y creando así el universo en el que los grupos humanos viven y en 
el que producen eso que llamamos cultura y conocimiento. El imaginario colectivo de cada tribu, de cada grupo humano, es en cada momento la "matriz de la que se alimentan los sentidos, el pensamiento y el comportamiento; acota lo que, en cada caso, puede verse y lo que no puede verse, lo que puede pensarse y lo que no puede pensarse, lo que puede hacerse y lo que no puede hacerse [...] lo que es posible y lo que es imposible" (Lizcano, 2003, p. 14).

Todas las actividades humanas se nutren, de una $u$ otra manera, del imaginario colectivo de cada época. Es por lo tanto razonable que, si algo sustancial ha mudado en él, dicho cambio se revele simultáneamente en varios ámbitos de la cultura. La ciencia y la literatura se abastecen de ese imaginario colectivo y a la vez lo abastecen. No sorprende así que ciertos conceptos puedan ser "recogidos" y amplificados en sincronía por las dos, con los elementos propios de cada una de ellas. Tendremos en consecuencia dos productos diferentes, uno científico y otro literario, que responden en el fondo al desarrollo de una idea germinal común.

La literatura y la ciencia son dos de las áreas que más "material" aportan al imaginario colectivo (al menos en la cultura occidental). Nada más natural, entonces, que el que las nociones literarias o científicas repercutan también en otras áreas de la cultura. Este modelo permite asimismo comprender mejor algunos aspectos relevantes de las relaciones entre literatura y ciencia. Por ejemplo, lo que llamamos habitualmente "anticipaciones literarias de la ciencia" no es otra cosa que la incorporación al imaginario colectivo de ciertas ideas con origen en la literatura que luego la ciencia (o cualquier otra práctica) tomará para sí. En lugar de anticipaciones (ya sean literarias o científicas) deberíamos hablar más bien de creaciones de cada campo que, una vez disueltas en el imaginario colectivo, pueden ser asimiladas y utilizadas en otro espacio cualquiera de la cultura. En efecto, asumir que se trata de anticipaciones significaría creer en una inexorable determinación del progreso científico (solo es anticipable aquello que inevitablemente ocurrirá). Ahora bien, el desenvolvimiento de las ideas, del pensamiento y de la cultura no parece algo inexorable, ni por ende tampoco fácilmente predecible; y se piensa además que la ciencia "constituye" el mundo al menos tanto como lo "descubre", lo que reduce aún más su anticipabilidad.

El imaginario colectivo es, así pues, el lugar clave para explorar las vinculaciones entre literatura y ciencia. Pero, ¿cómo organizar la exploración del imaginario?, ¿cómo investigar la realidad imaginaria del imaginario? El primer paso consiste en saber dónde buscar afluentes de lo imaginario. En este sentido, es primordial tener en cuenta que "Lo imaginario [...] no está solo allí donde se lo supone, en los mitos y los símbolos, en las utopías colectivas y en las fantasías de cada uno. Está también donde menos se lo supone, incluso en el corazón mismo de la llamada racionalidad" (Lizcano, 2003, p. 13). No debemos olvidar aquí que debajo de cada idea o concepto (tanto en literatura como en ciencia) late una metáfora, una metáfora que, como sugería Nietzsche, se ha olvidado de que lo es (Díaz y Heler, 1992, p. 108). Y son justamente tales metáforas las que nos abren pequeñas grietas por donde aventurarnos a explorar el imaginario. Si partimos de un concepto o una idea (ya sea esta científica o literaria) y seguimos su débil hilo, que se pierde de vista en las profundidades del imaginario, percibiremos que la identidad de esa idea o de ese concepto se desvanece, que sus contornos se difuminan y sus características se desagregan. Una vez allí, el camino inverso hacia la superficie nos conducirá a una novela o a una teoría científica, a un poema o a un concepto matemático, a buscar un nuevo sistema de referencia o a reemplazar el narrador omnisciente o a abandonar la perspectiva y abrazar el cubismo o la pintura abstracta. Como comprobaremos a continuación, muchas veces una misma intuición primigenia, brotada del magma del imaginario, se expresa a la vez y de modos plurales en diferentes ámbitos de la cultura y del conocimiento.

\section{AUTORREFERENCIALIDAD EN LITERATURA Y CIENCIA}

El impresionismo, el cubismo y diversas formas de pintura abstracta efectúan a principios del siglo XX un corte drástico con la tradición figurativa. Nace otra mirada al mundo, la cual condice en la literatura con otras técnicas y perspectivas: ficciones que trasportan ante todo una realidad verbal (Joyce, Lezama Lima, Guimaraes Rosa, etc.) y cuyas referencias históricas o sociales parecen, en ciertos momentos, una especie de excusa; ficciones en las que las palabras buscan independizarse y ser su propio fin; ficciones donde la literatura comienza a mirarse a sí misma y a convertirse en su propio objeto de estudio. Pero también otras que abandonan el ideal flaubertiano del narrador invisible y más o menos objetivo para poner el acento no solo en un punto de vista cada vez más marcado (en la dependencia del observador), sino también en una polifonía de múltiples focos, en un narrador ultravisible (la marginalizada tradición del exceso a lo Sterne) o principalmente en una acentuada autoconciencia: unas ficciones que todo el tiempo recuerdan y aceptan su condición de artefacto literario. Bajo inspi- 
ración científica, Roman Jakobson introduce en 1959 el concepto de metalenguaje, y Roland Barthes el de metaliteratura. En 1970 el escritor William Gass utiliza por primera vez el término metaficción, basándose en la idea de que "Hay metateoremas en matemáticas y en lógica; la ética tiene su superespíritu lingüístico; en todas partes se idean jergas para departir sobre jergas, y no ocurre de otro modo en la novela" (Gass, 1970, p. 136). Conviene, no obstante, mencionar una sutil diferencia entre la tradicional metaliteratura y la denominada metaficción del siglo XX y XXI. La primera, aun cuando acceda al primer plano en obras contemporáneas como Si una noche de invierno un viajero de Italo Calvino, etc., ya existía en Cervantes o Jane Austen y en su "ironía romántica" -lo han apuntado André Brink o David Lodge-. La segunda, la metaficción actual, además de aludir autorreferencialmente a sí misma a través de variadas estrategias, entre ellas la de narrar el propio proceso creativo o la de mostrar explícitamente los elementos que posibilitan el discurso ficcional, suele ir más allá, cuestionando los vínculos entre realidad y ficción y especulando sobre la imposibilidad de conocer objetivamente el mundo.

Por esos mismos años, a principios del siglo XX, la lógica matemática estaba igualmente examinando problemas relacionados con la autorreferencialidad, como si a lo largo de su propio desarrollo la lógica se encontrara finalmente consigo misma. Pero ¿qué hay de novedoso en que un sistema hable de sí?, ¿qué sucede cuando el objeto de estudio coincide con el sujeto que lo estudia?, ¿qué pasa cuando la lógica o la literatura se auto-observan? Existe en lógica una famosa paradoja, atribuida a Epiménides, que en su versión original reza: "Todos los cretenses son mentirosos", y que en su forma resumida puede leerse como "Esta afirmación es falsa". Tal dicho contradice categóricamente la idea intuitiva de que toda predicación ha de ser o bien verdadera o bien falsa. No hay manera de afirmar que la de Epiménides sea verdadera o falsa: es sencillamente indecidible. Hasta aquí, no se trataría más que de una curiosidad lógica. Sin embargo, es el tipo de paradoja que puede aparecer también cuando la matemática se mira a sí misma. Kurt Gödel, uno de los lógicos más destacados de todos los tiempos, decidió utilizar el razonamiento matemático para estudiar el propio razonamiento matemático, y se encontró con que en determinados sistemas formales siempre es posible declarar a propósito de al menos un enunciado que "este enunciado no es demostrable". Ello permitió a Gödel presentar el primero de sus famosos teoremas de incompletitud, "Toda formulación axiomática de teoría de los números incluye proposiciones indecidibles", cuyo significado es, ni más ni menos, que siempre existirán enunciados matemáticos, como los hay lingüísticos según la paradoja de Epiménides, de los cuales no podremos saber si son verdaderos o falsos. La introspección matemática arrojando piedras sobre su propio tejado.

Durante todo el siglo XX se observó una curiosa convergencia de literatura, ciencia y autorreferencialidad en la crítica literaria. La "nueva crítica", aparecida a principios de siglo, intentó asentar sus ideas en términos racionales y sistemáticos imitando el método científico. Los así llamados formalistas rusos (desde Shklovski hasta Jakobson) promocionaron un abordaje científico, novedosamente riguroso, de las letras, siguiendo el cual un "narratólogo" como Propp analizó la estructura del cuento popular (los "puntos recurrentes" en los cuentos de hadas) y otros investigadores ahondaron en el análisis de la trama o en el efecto de extrañamiento ("desfamiliarización") que suscitan ciertas metáforas. Unos años más tarde, Ferdinand de Saussure propondría lo que se considera el primer intento de sistematizar la lingüística. Saussure desarrolló una "ciencia del lenguaje" a la que hoy se denomina semiótica. Para Saussure, el lenguaje constituye un sistema de términos interdependientes donde el valor de cada término se establece solo en relación con la presencia simultánea de los otros (Saussure, 1945). Es lo que se conoce como estructuralismo. Sin embargo, hacia mediados de los años 60 , el estructuralismo comenzó a acusar el peso de las objeciones y sus limitaciones se hicieron evidentes. Jacques Derrida defendió entonces una aproximación original a la lectura de los textos literarios que difería de la "nueva crítica" y del estructuralismo pero que, a la vez, tomaba prestados algunos elementos de ellos (Culler, 1998, p. 11). La estrategia de deconstrucción diseñada por Derrida subrayó la dificultad de encontrar un significado absoluto en los textos literarios, lo cual otorgaba al lector un papel más activo y le advertía no solo de la existencia de múltiples interpretaciones, sino también de la arbitrariedad de fijar una que fuera la correcta. En definitiva, la teoría literaria, buscando en el método científico bases sólidas sobre las que asentarse, descubrió que los textos literarios son indecidibles (Kau, 2001). En algún sentido (y sin entrar en peligrosas comparaciones), Derrida fue para la literatura lo que Gödel para las matemáticas.

Probablemente Derrida no conocía las ideas de Gödel; $y$, de todas maneras, sus propuestas no se derivan de los trabajos de este. Lo interesante del caso es la simultaneidad: el hecho de que, en tres o cuatro dé- 
cadas (es decir, desde una perspectiva histórica, casi al mismo tiempo), la incertidumbre y la indecidibilidad aparecieran en tanto protagonistas inesperados en varios ámbitos del conocimiento. Como nos recuerda Douglas R. Hofstadter en su libro Gödel, Escher y Bach, "Todo lenguaje, todo sistema formal [...] todo proceso de pensamiento desemboca, tarde o temprano, en la situación límite de la autorreferencia: de querer expresarse sobre sí mismo." (2001, p. 683).

\section{LA LITERATURA Y EL MÉTODO CIENTÍFICO}

Otro buen ejemplo de las interacciones entre literatura y ciencia es la introducción del método científico en la literatura de ficción, y más precisamente en las novelas policíacas o detectivescas. Desde sus orígenes, en las primeras décadas del siglo XIX, la novela policíaca ha estado siempre íntimamente ligada a "lo científico" y a su capacidad para explicar el mundo. El detective debe afrontar la resolución del caso basándose en los hechos, analizando la información disponible, elaborando teorías y contrastando sus hipótesis con la realidad. El detective se convierte entonces en una especie de alter ego del científico, que logra finalmente dilucidar cualquier problema por complejo que pueda parecer. La literatura se apropia así de una visión lógico-positivista de la realidad que se reflejará en buena parte de su producción y que influirá fuertemente el modo en que los lectores (y por extensión, la sociedad) perciben el mundo.

Es lícito considerar a Edgar Allan Poe como el padre del género policíaco, o al menos como el aglutinador de ciertas ideas que "estaban en el aire" de la época. En particular, su relato Los crímenes de la calle Morgue (1841) marca el comienzo de un nuevo tipo de literatura que se prolonga hasta nuestros días y que, casi al mismo tiempo, tanteaba también el inglés WiIkie Collins en La piedra lunar (1868). Poe introduce en sus textos, para la resolución de diferentes crímenes, una clase de análisis que la policía de entonces difícilmente podría haber imaginado. De hecho, los agentes de la ley aparecen retratados como sujetos mediocres, sin imaginación y hasta torpes. Es solo mediante la observación y la deducción lógica como el detective (el investigador) llegará a esclarecer el caso y a establecer la verdad. Al contrario que a los policías, al investigador se lo pinta generalmente perspicaz, culto y, en muchos casos, amante de la ciencia. La identificación del lector con la figura del investigador de aquella época se consolida de inmediato, y el lector sabe también que es solo cuestión de tiempo que el detective acceda a la verdad.
Poe ha ejercido una inmensa influencia en los escritores que le sucedieron; por ejemplo, sobre Arthur Conan Doyle, con su inolvidable Sherlock Holmes. Conan Doyle era médico y, de hecho, fue uno de sus profesores en la Universidad de Edimburgo, Joseph Bell, quien le inspiró la figura de Holmes. El doctor Bell (como luego el asombroso Padre Brown, de Chesterton) era capaz de hacer diagnósticos con solo observar los modales del sujeto o las características de su vestimenta, llevando de este modo el método lógico-deductivo a la cima del género. Desde los inicios del género policíaco, y durante más de cien años, dicho método ha acompañado la corriente positivista que surgió primero en Francia (Auguste Comte) y luego en Inglaterra (John Stuart Mill) y que se extendió a la postre por toda Europa. El género se sustenta en un positivismo, y al mismo tiempo lo fomenta, que se auto-erige en la única vía para alcanzar un conocimiento verdadero del mundo a partir del análisis de hechos verificables.

Señalemos que en todo este período "positivista" del género policíaco se utilizó (casi) siempre un narrador omnisciente o bien un narrador testigo, pero fiable, certero. La opción de dejar no resuelto un caso resultaba inconcebible para el imaginario colectivo de la época, y no hubiese sido admitida. La infalibilidad del método era un axioma aceptado tácitamente tanto por los autores como por los lectores. Como ya hemos evidenciado antes, lo que no participa del imaginario colectivo de un corte histórico no puede ser pensado y mucho menos representado. Sea de ello lo que sea, las evoluciones en el imaginario colectivo están en gran medida promovidas, lo constataremos a continuación, por la literatura y la ciencia de cada época.

A diferencia de la literatura fundada en el principio de "suspense" (donde la intriga reside en lo que ocurrirá en el futuro), el género policíaco se basó especialmente en el principio del "enigma"; esto es, en explicar hechos ya ocurridos, por lo común un crimen o un asesinato que semejaban (a primera vista) imposibles de aclarar. Más tarde se fueron incorporando variaciones de la trama y del argumento que respondían más a variaciones del canon estético o a la importación de elementos del campo científico que al reflejo de la realidad circundante. Aparece, por ejemplo, el asesino en serie (con figuras míticas como Landru o Jack the Ripper). En tales sucesos no se trata tanto de explicar lo ocurrido como de encontrar patrones de comportamiento que eviten el próximo asesinato. Pasamos así de la mera explicación del caso preceden- 
te a la predicción o anticipación del próximo; o mejor dicho, a una mezcla de enigma y suspense. Un ejemplo extremo de anticipación criminal lo constituye el relato de Philip K. Dick El informe de la minoría (The Minority Report, 1956), en el que unos seres con el don de presagiar el futuro son utilizados por la policía para prever el crimen y para combatir los asesinatos antes de que ocurran.

En resumen, a lo largo de casi dos siglos, la novela policíaca ha ido asimilando elementos del mundo de la ciencia, y la figura del detective ha estado siempre vinculada a la imagen del científico y a su particular acercamiento a la realidad. La novela policíaca y el método científico se vuelven así (en algún sentido) casi indistinguibles, y sostienen un imaginario colectivo por el que a su vez son sostenidos, el cual refuerza la idea de que la razón y una determinada metodología son competentes para solucionar cualquier tipo de problema. Sin embargo, una vez que el método científico se introduce en la literatura, esta se independiza de la ciencia y se permite concebir nuevas hipótesis. La apropiación literaria del método científico facilita que tanto escritores como lectores se planteen preguntas acerca de este último que no hubieran sido posibles en otros campos. La ciencia utiliza el método científico sin cuestionarlo; la filosofía puede cuestionarlo sin necesidad de utilizarlo; la literatura, en cambio, se toma ciertas libertades frente a la ciencia o a la filosofía, como las de parodiar y hasta contestar el método científico. Es cabalmente esta libertad de la ficción la que fabrica cristalizaciones del imaginario colectivo que favorecen una renovación de la visión del mundo. La literatura se constituye así en un lugar privilegiado para la indagación profunda de nuevas ideas a partir de conceptos muy arraigados en el imaginario. Sin el rigor científico o filosófico que exige la contrastación experimental o la coherencia interna, la verosimilitud literaria legitima un tipo de pesquisa más abierto y con menos ataduras respecto de lo "real". La ficción literaria autoriza a arriesgar hipótesis (incluso inverosímiles) que en otros entornos de pensamiento serían literalmente impensables.

En los últimos años se han publicado una serie de relatos literarios que examinan con lupa temas tan relevantes como la construcción (o la existencia) de la verdad o la determinación unívoca de un culpable a partir de una serie de hechos. Es lo que se conoce como "novela anti-policíaca", en la que los planteamientos narrativos del género policíaco convencional son subvertidos y el lector desempeña un papel más activo. En la novela anti-policíaca, el detective no es infalible, y muchas veces la resolución del caso es solo una entre otras muchas posibles. A diferencia del Ilamado "neopolicíaco" (que suele colocar el énfasis en el contexto social), la novela "antipolicíaca" pone en tela de juicio, no siempre por medio de la parodia, el principio del bien y del mal, la idea de "centro" o de orden establecido (impugnación bastante usual en la ficción "posmoderna") y hasta la propia naturaleza de la actividad policial y criminal. Tales transgresiones fueron practicadas por escritores ajenos al género, desde Bioy Casares y Borges, con su antidetective Isidro Parodi, hasta Thomas Pynchon, Vladimir Nabokov o el Paul Auster de la Trilogía de Nueva York, por citar algunos ejemplos en su mayoría "deconstructivos", donde la solución al misterio es escamoteada al lector o dejada abierta mucho antes del final del libro; donde se escuchan, en definitiva, más preguntas que respuestas.

Crímenes imperceptibles (editado en España como Los crímenes de Oxford, 2004) de Guillermo Martínez manifiesta expresamente dudas sobre la posibilidad de alcanzar la verdad. Uno de los ejes argumentales de la novela pasa por el mencionado "teorema de incompletitud" de Gödel, en el que se declara que si un sistema es consistente, entonces es incompleto; es decir, que en él existirán siempre proposiciones de las que no podrá saberse si son verdaderas o falsas. Otra novela reciente, que va incluso un paso más allá, es Tesis sobre un homicidio de Diego Paszkowski (1998). En este caso se despliegan elementos inconcebibles hace cincuenta años, por ejemplo la idea de que arrancando de unos mismos hechos es factible encontrar dos (o más) explicaciones que conduzcan a distintos culpables. En ella se sugiere no solo la imposibilidad de fijar la verdad, sino también la idea de que esta puede ser tan solo una proyección de nuestras obsesiones; y de que, presos de pareja obsesión, podemos confundir casualidades con causalidades.

Todos estos cuestionamientos sobre los caminos por los que es posible (o no) llegar a la verdad se van a incorporar al imaginario colectivo desde la literatura. Es precisamente la libertad discursiva de la literatura la que le permite trabajar en la ficción con hipótesis en principio inimaginables desde el paradigma dominante. Como comentamos más arriba, una vez que el método científico se integra en la literatura, la literatura puede potenciarlo, pero también ponerlo en la picota. Y entonces se insinúa la pregunta inevitable: ¿están proponiendo las nuevas narrativas una revisión del método científico y de nuestra manera de comprender el mundo? 


\section{CAMBIOS DE PARADIGMA}

Hacia comienzos del siglo XX se produce en la cultura occidental un conjunto de metamorfosis en la visión del mundo que van a dejar una señal radical en la ciencia, la literatura y el arte de los siguientes cien años. Se diluyen los sistemas de referencia absolutos en la física con la teoría de la relatividad (1905), la perspectiva en la pintura con la introducción del cubismo (1907), y la música tonal con el abandono del tono fundamental y la armonía. En el terreno literario, el realismo "naturalista" de Émile Zola (circa 1880) semeja una cumbre o una suerte de cul-de-sac (callejón sin salida) para cierta metodología objetivo-científica. A este tipo de realismo se le contraponen, a partir del final del siglo XIX, otros caminos: la "focalización" cada vez más limitada (Henry James), la dependencia de la memoria (Proust), la subjetividad extrañada de Kafka, y el monólogo interior de Joyce. Tales cambios de paradigma vendrán a alterar drásticamente el imaginario colectivo.

La ficción del siglo XVIII y XIX fue escrita y leída en un mundo cuyos paradigmas eran los de Galileo, Newton y Laplace: es decir, en una sociedad determinista, con un sistema de referencia espacio-temporal absoluto y con la potencialidad imaginaria de conocerlo todo. En la literatura esto se reflejaba, por un lado, en la figura del narrador omnisciente (el narrador que también lo sabe todo, como un dios); y por otro lado, en las posibilidades de la trama narrativa tradicional, la llamada "trama energética", donde los hechos se encadenan lógicamente y la voluntad o el deseo de un personaje central pone en marcha la acción y se topa con un conflicto que es, a menudo, una voluntad contraria, sea esta última colectiva o individual.

Desde finales del siglo XIX, el narrador omnisciente cede paulatinamente su lugar a otros tipos de narrador cuya perspectiva es más limitada (semi-omnisciencia) y más subjetiva, o cuya autoridad se antoja incluso poco (o nada) fiable, pues la propuesta de lectura alimenta la desconfianza ante los presupuestos más ortodoxos. Estas alteraciones coinciden temporalmente con el aludido abandono, por parte de la física, de los sistemas de referencia absolutos (teoría de la relatividad), y con la introducción del principio de incertidumbre (mecánica cuántica). El siglo XX privilegiará asimismo otros cambios de paradigma: lo no lineal frente a lo lineal, lo caótico frente a lo determinista, las estructuras en red (lo rizomático) frente a las estructuras jerárquicas. Los nuevos paradigmas estimulan en la literatura la concepción de cadenas causales más aleatorias, de interconexiones menos inteligibles y más misteriosas, de formas más inciertas y fragmentadas, de tramas más inestables e indeterminadas. La obra novelística de William Faulkner da buena prueba de ello: pluralidad de narradores, pluralidad de puntos de vista, pluralidad de tiempos, trama-puzzle (acciones independientes, renuentes a la cronología, aunque entrelazadas), una prosa enmarañada y hasta el ardid de presentar (en El sonido y la furia, 1929) dos personajes diferentes con un mismo nombre.

El nuevo marco teórico propicia la coexistencia de orden con desorden, así como un más amplio espectro de vínculos entre causas y efectos, sobre todo en términos cuantitativos: menor tendencia a que las causas y los efectos resulten sensatamente proporcionales, mayor inclinación a presentar causas pequeñas que suscitan grandes efectos (el llamado "efecto mariposa"), o lo contrario. El azar y lo arbitrario ingresan, a lo largo del siglo XX, tanto en el mundo de la ciencia como en el del arte, que antes solían condenar su aparición como un mero Deus ex machina ${ }^{3}$. Difícil decir en qué mundo ocurrió la primera gran aceptación. Como ya hemos dicho antes, las mutaciones profundas del imaginario colectivo suelen revelarse en paralelo en ámbitos plurales de la cultura y del conocimiento.

Otros de los grandes cambios de paradigma que se produjo a principios del siglo XX está relacionado con la posibilidad de operar con diferentes lógicas. Durante más de veinte siglos fue la lógica aristotélica la que forjó un estilo particular de ver y pensar el mundo, y la que asentó ciertas verdades absolutas, ligadas a principios o axiomas indiscutibles. En torno a 1900 aparecen lógicas renovadas como la lógica plurivalente, la intuicionista o la dinámica, entre otras. Como contrapartida, en el campo literario, casi al mismo tiempo que estalla en Inglaterra la corriente del nonsense (Edward Lear y Lewis Carroll), el poeta francés Alfred Jarry inventa la patafísica, que consiste en una "ciencia" de las excepciones. Pariente audaz de la "lógica del absurdo" (la reductio ad absurdum de los romanos, la apagogía de los griegos), será el punto de partida para el dadaísmo y el surrealismo tanto como para el teatro de lonesco o de Samuel Beckett. Por otra parte, André Gide, evadiéndose de las imposiciones de la lógica narrativa tradicional, siembra en su obra elementos arbitrarios, ya sea en la trama ya en las motivaciones de los personajes. Lo hace especialmente en Los sótanos del Vaticano (1914), donde introduce lo que se denomina el "acto gratuito": una acción que rompe la lógica del relato, pero que es determinante en la novela. Las transformaciones enumeradas se reflejan 
en el nivel gramatical en que la construcción de las frases según la norma lingüística deja paso a técnicas donde el razonamiento es menos lógico y lineal. Un corte radical puede advertirse en la explosión del llamado "monólogo interior" y de su versión más extrema, el "flujo de conciencia" (Edouard Dujardin en Han cortado los laureles, Virginia Woolf en Mrs. Dalloway), el cual intenta reproducir el pensamiento vivo dentro de la mente humana, con su cuota de inconsciente y de asociaciones libres. La huella del psicoanálisis resulta muy evidente en tal sentido y no causa mucho asombro que se dijera de Arthur Schnitzler (maestro pionero de tales técnicas en su novela $L a$ señorita Elsa) que fue un alma gemela de su conciudadano Sigmund Freud. Schnitzler y Freud exploraban un mismo problema: uno desde la literatura y el otro desde la medicina (ciencia).

¿Son las anteriores meras coincidencias entre el arte, la literatura y la ciencia de principios del siglo $X X$ ? ¿Estaban Picasso, Joyce y Einstein explorando en última instancia los mismos conceptos? ¿Hay alguna conexión entre el psicoanálisis, el narrador subjetivo y la relatividad? Es difícil hablar aquí de una relación causal, de influencias recíprocas o incluso de apropiaciones. Nos parece más adecuado hacerlo de la "emergencia" de una nueva forma de ver el mundo, de una confluencia de ideas y sucesos que ha dado lugar a un cambio de paradigma cultural (en su más vasta acepción), y que ha repercutido de manera diferente y concomitante en cada disciplina.

\section{DISCUSIÓN}

Los casos que acabamos de repasar nos enseñan que existen profundos vínculos intelectuales entre literatura y ciencia, vínculos a veces sutiles, a veces más explícitos, anudados como consecuencia de que ambas proceden de un imaginario colectivo compartido. Gracias a ellos hemos podido comprobar que, a lo largo de los últimos dos siglos, una y otra han reflexionado acerca de unos mismos temas, y tratado alternativamente ciertos conceptos (por ejemplo, los propios de la visión lógico-positivista del mundo, etc.). La cartografía (parcial) de dichas relaciones nos ha invitado a delimitar zonas de confluencia y a encontrar nociones e intuiciones que puedan ser examinadas con un enfoque transdisciplinar. Hemos comenzado a vislumbrar apenas la inmensa frontera entre ellas.

La exploración de ese espacio fronterizo, de esa terra incognita del conocimiento no solo es necesaria, sino también deseable y sugerente. Sin embargo, la tarea no es sencilla. Una de las principales dificulta- des a la hora de abordar las relaciones entre literatura y ciencia reside en el establecimiento de un lenguaje común. Parece probable que, al igual que ocurre con el conocimiento, la parcelación del lenguaje en discursos excluyentes (lenguaje poético/lenguaje científico, etc.) sea una división arbitraria y contingente. Es indispensable por lo tanto indicar puntos de contacto buscando, también en el lenguaje, raíces profundas comunes que faciliten el entendimiento. Otro problema de entidad es la delimitación del objeto de estudio. El pensamiento analítico exige la división del objeto en componentes más elementales, mientras que el pensamiento holístico se opone a dicha fragmentación. En nuestro caso, pensamos que habría que procurar no renunciar a la visión holística ni volver tampoco inútil el análisis. El desafío no es trivial: los estudios fronterizos serán diferentes o no serán. Como en toda nueva área del conocimiento, los métodos de estudio deberán redefinirse, de suerte que ofrezcan dispositivos discriminantes claros respecto de los ya existentes, y también que sus resultados se alejen de todo lo consabido, por ejemplo que no sean ni completamente predictivos ni totalmente descriptivos.

En cuanto a las estrategias generales adecuadas para cerner las interacciones entre literatura y ciencia, muchos de los estudios actuales en esta materia optan o bien por la conquista o bien por la división del territorio del conocimiento. En el primer caso, una de las disciplinas intenta absorber a la otra: es lo que ocurre con el positivismo (que pretende reducir la literatura a la ciencia), o con el postmodernismo radical (que pretende reducir el discurso científico a un texto). En el segundo caso, pareciera que se busca un mutuo "pacto de no agresión" entre disciplinas para repartirse el terreno, y para que cada una subsista tranquila y sin demasiada fricción con la otra. Nosotros proponemos aquí una vía alternativa: trabajar en la frontera. No en una frontera-muro que divida sectores irreconciliables, sino en un espacio abierto que represente una zona de transición; una región donde convivan conceptos propios de cada campo, pero en la que también quepa encontrar ideas nuevas que, concerniendo solo a la frontera, no pertenezcan a ninguno de los dos campos. Es precisamente en esa región fronteriza donde los intercambios son más intensos, y por ello esta terra incognita está en condiciones de constituir una zona intelectualmente rica y estimulante ${ }^{4}$.

La literatura y la ciencia ya no pueden darse la espalda. Por un lado, la especialización de la ciencia ha profundizado el conocimiento sobre determinados 
dominios, a la vez que su reduccionismo la ha alejado de las cuestiones realmente complejas. Somos capaces de manipular el ADN, pero no sabemos aún cómo nuestro cuerpo condiciona nuestro pensamiento; somos capaces de activar neuronas individuales, pero no sabemos aún por qué soñamos. No es posible tratar la complejidad solo desde una perspectiva reduccionista; se necesita una integración del conocer, una hibridación de las disciplinas. Ahora bien, la hibridación no es una meta, sino un punto de partida, un lugar desde donde construir formas epistémicas inéditas, desde donde comenzar a contemplar y aprehender los problemas complejos. Por otro lado, es evidente también que a la literatura no le está permitido ignorar las ideas científicas, y mucho menos en la medida en que la ciencia se aventure a explorar territorios tradicionalmente asignados al mundo de las humanidades. Así, los últimos descubrimientos en torno al funcionamiento del cerebro, a las características de la conciencia o a las trampas de la memoria deberían servir para enriquecer las formas literarias más que para volverlas opacas; y el tratamiento literario de esos temas debería asegurar, por su parte, un contrapunto crítico y ético a la investigación científica.

Las disciplinas son necesarias y seguramente seguirán existiendo. Se trata ahora, más que de destruir lo que ya existe, de deconstruirlo. En tal sentido, creemos que es imprescindible e irrenunciable promover trabajos de investigación en la frontera entre disciplinas porque es allí donde con mayor probabilidad se producirán avances en nuestra manera de comprender el mundo. La ciencia y la literatura, incluso cuando abordan los mismos temas, utilizan lenguajes distintos y métodos complementarios. Y es finalmente esa diferencia metodológica la que enriquece la interacción entre ambas. La solución a los problemas complejos no pasa ya por la vieja disputa entre holismo o reduccionismo, sino por una integración de ambos. Necesitamos exploradores de la frontera, mercaderes de ideas, traficantes de conceptos, intelectuales que se aventuren en una tierra desconocida que no será firme pero sí fértil, y con un potencial humano e intelectual nunca visto hasta ahora.

\section{AGRADECIMIENTOS}

G. A. S. agradece al Donostia International Physics Center el apoyo institucional y económico al Proyecto Mestizajes, en cuyo marco ha sido escrito este artículo. E. B. agradece al Donostia International Physics Center la estancia de seis meses en San Sebastián dentro del Programa Escritores en Residencia del Proyecto Mestizajes.

\section{NOTAS}

1. T. H. Huxley era un distinguido naturalista inglés, y M. Arnold un destacado hombre de letras de la Inglaterra victoriana. Ambos sostuvieron a través de dos conferencias sucesivas (Huxley, 1880; Arnold, 1882) una intensa aunque civilizada discusión acerca del contraste entre una educación literaria y una educación científica.

2. Puesta en abismo: procedimiento narrativo que consiste en imbricar una

\section{BIBLIOGRAFÍA}

Culler, J. (1998). Sobre la deconstrucción. Madrid: Cátedra.

Díaz, E. y Heler, M. (1992). Hacia una visión crítica de la ciencia. Buenos Aires: Biblos.

Gossin, P. (ed.) (2002). Encyclopedia of Literature and Science. London: Greenwood Press.

Gass, W. H. (1970). Fictions and Figures of Life. New York: Alfred A. Knopf.

Hoftadter, D. (2001). Gödel, Escher y Bach. Barcelona: Tusquets. narración dentro de otra; muchas veces esas narraciones son similares entre sí, pero a diferentes escalas.

3. Del griego dios de la máquina, expresión empleada para aludir a un elemento externo que resuelve una historia de manera algo sencilla o con un golpe de efecto, sin atender a la lógica de la trama narrativa.

4. Si bien escapa a los objetivos de nuestro estudio, nos parece preciso

Kau, A. (2001). Deconstruction and Science: How post-structuralist literary theory applies to scientific understanding. [En línea]. Disponible en: https://goo.gl/DeqSbR

Lamb, D. y Easton, S. M. (1984). Multiple Discovery: The Pattern of Scientific Progress. Amersham: Avebury Press.

Lizcano Fernández, E. (2003). Imaginario colectivo y análisis metafórico. Conferencia inaugural del I Congreso Internacional de Estudios sobre Imaginario y Horizontes Culturales que se celebró en la Universidad Au- mencionar que no solo la ciencia y la literatura están en condiciones de interactuar para ampliar su campo del conocimiento, sino que también pueden hacerlo las disciplinas que estudian la ciencia y la literatura. Así, la epistemología y la crítica literaria no deben desdeñarse mutuamente si pretenden avanzar en el estudio de temas complejos.

tónoma del Estado de Morelos, Cuernavaca, México, del 6 al 9 de mayo de 2003. Disponible en: http://www.unavarra.es/puresoc/ pdfs/c_salaconfe/SC-Lizcano-2.pdf

Saussure, F. de (1945). Curso de lingüística general. Buenos Aires: Losada.

Snow, C. P. (2000). Las dos culturas. Buenos Aires: Nueva Visión.

Watson, P. (2002). Historia intelectual del siglo XX. Barcelona: Crítica. 